\title{
Integrated Family Assessment and Intervention Model: A Collaborative Approach to Support Multi-Challenged Families
}

\author{
Ana Teixeira de Melo $\cdot$ Madalena Alarcão
}

Published online: 4 November 2011

(C) Springer Science+Business Media, LLC 2011

\begin{abstract}
In this article we describe the Integrated Family Assessment and Intervention Model (IFAIM), a multi-systemic, collaborative, strength-based, and family-focused in-home approach developed and implemented in Portugal. IFAIM is designed to assess and to support multi-challenged poor families, commonly known as multi-problem families, at psychosocial risk, with maltreated or neglected children. It integrates clinical, educational, social, community and forensic concerns, and practices under a systemic, narrative, and collaborative umbrella. IFAIM's theoretical foundations and background, its main characteristics, stages of implementation, and research directions are described and a case illustration is presented.
\end{abstract}

Keywords Child maltreatment - Collaborative practices - Integrative model · In-home family therapy $\cdot$ Multi-challenged families

\section{Introduction}

Multi-challenged families (Melo and Alarcão 2010), also known as vulnerable, multiproblem, multi-stressed families, or families in extreme distress (Cancrini et al. 1997; Madsen 2007; Sharlin and Shamai 2000; Walsh 2006a, b), have to cope with multiple internal and external stressors, often associated with harsh developmental and living conditions. Many have several basic unmet needs and are constantly challenged to change and to adapt to multiple external (e.g., finding a job with poor qualifications; dealing with poor environmental living conditions; keeping children safe in unsafe neighborhoods) and internal perturbations (e.g., negotiating roles and responsibilities in the face of external

\footnotetext{
A. Teixeira de Melo $(\bowtie)$

Foundation for Science and Technology, Faculty of Psychology and Education Sciences,

University of Coimbra, Rua Camilo Vaz, n. ${ }^{\circ} 45,3^{\circ}$ Dto. Centro, 4430-686 Vila Nova de Gaia, Portugal

e-mail: anamelopsi@gmail.com
}

M. Alarcão

Faculty of Psychology and Education Sciences, University of Coimbra, Rua do Colégio Novo, Apartado 6153, 3001-802 Coimbra, Portugal 
challenges with poor communicational resources; balancing special needs of an individual with the family's needs; and educating children with little available time to dedicate to them) through complex interactions.

Traditional models and settings of family therapy may be inadequate or insufficient to meet the complex needs of these families, particularly for those living in poverty (Frankel and Frankel 2007; Grimes and McElwain 2008; Rojano 2004; Sessions and Lightburn 2006). Conceptualization of their internal dynamics must necessarily be integrated in a broader ecological and multi-systemic framework due to the central role of environmental, social, and cultural factors in problem emergence and problem maintenance. Therefore, therapeutic interventions cannot ignore them and, on the contrary, should consider how to coordinate their action with other services (e.g., social, educational, community-focused).

In fact, multi-challenged families call for a broadening of the role of the therapist. He or she should work cooperatively with other professionals or even integrate interdisciplinary teams so therapeutic actions can take advantage of and/or inform other forms of support in order to increase their efficacy. Therapists must work to establish and explore multiple connections with the community in order to help the family satisfy its needs and establish effective relations with stronger and strategically positioned systems (e.g., neighborhood, extended family, social welfare, community organizations) (Doherty and Beaton 2000; Rojano 2004). Advocacy and community interventions are also likely to be part of therapeutic action when working with multi-challenged families (Doherty and Beaton 2000).

Research has shown that community-based services may be more suited for multichallenged families experiencing poverty, particularly home-based services. Many obstacles to the family's involvement in a therapeutic process may be removed or minimized this way. In addition, there might be unique opportunities to help the family change during non-therapeutic encounters (e.g., sessions focused on social support, resource management, life and parental education) or during interactions with the family while its members perform daily routines and tasks in their home.

Multi-systemic approaches have shown positive results in the treatment of complex cases (Henggeler et al. 1992; Hogue et al. 2002). The efficacy of several of these different programs is probably associated with some common features such as: working from an ecological and systemic perspective; working with multiple systems; combining multiple components; and making use of strategies to promote the family's engagement (Sprenkle et al. 2009; Liddle 2004; Cunningham and Henggeler 1999). Most of these treatment programs are particularly suited for families with adolescents with behavioral problems, although a small number of studies have focused on child abuse and neglect (Barth et al. 2007; Brunk et al. 1987).

Community-based, in-home family therapy/preservation programs have received increased attention for being particularly suited to help harder-to-reach populations and families where abuse and neglect have occurred (Barth et al. 2007; Corcoran 2000). Strength-based, resilience oriented perspectives have been advocated as being particularly adequate to support populations experiencing multiple risks and different forms of adversity (Benard, 2006; Walsh 2006a, b) such as poverty. This orientation is present in many home-based interventions through which family strengths can more easily be identified and amplified (Benard 2006; Czyszczon and Lynch 2010; Lee et al. 2009).

Therapists in traditional office-based settings may experience difficulties in understanding the complexity of the family's life as well as its multiple needs. Consequently, they may have trouble communicating a genuine empathic understanding to the family. They can also easily feel disempowered and overwhelmed when confronted with urgent extra-therapeutic requests (e.g., access to food to guarantee a meal a day, money to buy medication for a child, help to find a job, access to child care). 
Further, the multiple recurrent crises experienced by these families may drive the therapist into a roller coaster of conflicting emotions and throw him or her off track. The therapist must be cautious not to be focused exclusively on the family's internal functioning and relations or on the urgency of other material/instrumental needs or requests and must find a delicate, dynamic balance between different needs. On the one hand, therapists must help the family address current needs associated with its economic and social conditions (e.g., finding a job, pursuing an education, making ends meet, accessing adequate child care, meeting health needs). On the other hand, families must be supported to develop greater reflexivity, creativity, and flexibility in order to reconstruct their internal behavioral, cognitive, and emotional patterns of functioning as well as the narratives that will enable them to create a positive foundation for resilient development.

Working with multi-challenged families is also a significant challenge to the therapist since he or she has to help the family adapt and grow in a context of limited options. These families tend to experience limited choices, and harsh consequences of a "bad choice" with few opportunities to make up for it (Arditti et al. 2010). "Cumulative disadvantage" (Arditti et al. 2010, p. 142) conditions narrow their opportunities for positive development and adaptation and often undermine a sense of authorship, autonomy, and positive identity, thereby disturbing the family's internal relationships, for example, in regard to parenting. Therapeutic work should acknowledge this and aim to help the family develop a greater sense of control over its life and skills to master many challenges. It should support the reconstruction of the family's identity and its internal organization while helping the family engage in effective actions aimed at altering its economic or social conditions and creating opportunities for positive development. Professionals must support families so they can understand and overcome the oppressive influence of poverty (Grimes and McElwain 2008) as well as help them pursue their preferred visions and directions in life (Madsen 2007; White 2007) while providing appropriate care to their children. However, some aspects of the family life may not be easily amenable to change (e.g., housing improvement, change of socioeconomic status). Still, therapy should also provide opportunities for the family to strengthen family resilience processes and foster hope for the future (Walsh 2006a, b).

In Portugal, programs with the above mentioned characteristics and strengths-based perspectives are far from dominant (Sousa and Eusébio 2005; Sousa et al. 2007). Although, importing and transferring evidence-based programs to the Portuguese context could be considered, several difficulties would persist or be raised anew. On the one hand, the costs probably would be unaffordable for most community-based organizations, which, in Portugal, are predominantly non-profit and face many financial difficulties. On the other hand, these programs probably would not meet core assessment needs in the context of the child protection system.

The child protection system in Portugal deals with difficulties in supporting families to change, but its professionals are also debating regarding the conduct of assessments (CNPCJR 2009; Torres 2008). While in several countries there has been considerable investment in the development of specific assessment frameworks and instruments (Baird and Wagner 2000; Department of Health 2000; MacDonald 2001; Reder and Lucey 1995), they are scarce in Portugal. Child protection professionals are not only poorly prepared to conduct assessments beyond the initial investigations, such as comprehensive risk assessments, assessments of parental capacity or family functioning, but they often experience an excessive workload that constrains their ability to do so.

In this article we aim to describe the Integrated Family Assessment and Intervention Model (IFAIM), which was designed predominantly for Portuguese family-centered services, particularly for the CAFAP (Centros de Apoio Familiar e Aconselhamento Parental [Centers for Family Support and Parental Counseling]), considering their resources and 
focus on at-risk families. IFAIM was developed to support change in multi-challenged families and the child protection system through the conduct of rigorous, though collaborative, assessments in cases of child abuse or neglect. First, we briefly describe IFAIM's main theoretical background and some of its core characteristic. Secondly, we present the objectives, procedures, and main characteristics of each of IFAIM's five stages of implementation (referral, reception, assessment, support for change and follow-up/closure) and, finally, we present a brief case example.

\section{The Integrated Family Assessment and Intervention Model (IFAIM)}

\section{General Description}

IFAIM is an integrative and collaborative family-centered assessment and intervention model. It has a (multi)systemic, ecological, strength-based orientation. IFAIM is implemented in a community-setting, privileging the family's home setting. An inter/transdisciplinary team is usually composed of at least one psychologist, a social worker, and a social educator. This model has emerged at the crossroads of clinical, social, community, and educational practices with the child protection and legal systems, incorporating contributions from several different approaches. It was specifically designed to meet the multiple needs of multi-challenged families at psychosocial risk with maltreated (physically or psychologically) or neglected children and youth.

IFAIM is organized to meet the needs of the Portuguese child protection system by preparing professionals in community-based family support services to conduct child protection assessments (e.g., parental capacity assessments), conforming with forensic and evidence-based recommendations (Budd et al. 2001; MacDonald 2001) and, therefore, rigorously reporting to the child protection system their outcomes in order to facilitate decision-making. The incorporation of a collaborative perspective and a focus on strengths and solutions (Berg and Kelly 2000; Turnell and Edwards 1999), unlike traditional forensic assessments, creates conditions to better assess the family's potential to change (Carr 2006; Cirillo and Di Blasio 1992; Fitzpatrick 1995) in those dimensions that are closely related to the child's safety and well-being. The adoption of systemic thinking in the context of child protection also contributes to the integration of different levels of analysis in these assessments while keeping a focus on the family and its change processes in order to increase the chances of success. Achieving an understanding in regard to the reasons that lead families to perpetuate a kind of functioning that limits its well-being and endangers the children demands an ongoing and intensive work of elaboration of systemic hypotheses (Carr 2006; Palazzoli et al. 1980; Relvas 1996; Vetere and Dallos 2003).

IFAIM is not only a family preservation program but also an assessment program. Therefore, cases may terminate at the end of assessment for a variety of reasons. When they continue to a support for change stage, unlike in traditional forensic assessments, the family continues to work with the same team that conducted the assessment. This team has developed in-depth knowledge about the family as it assisted it in engaging in a change process in the context of a respectful and transformative therapeutic relationship (Brown and Dean 2002). In those cases where family intervention is thought to be appropriate, families are invited to experiment with new ways of relating and possible solutions for their difficulties while receiving different forms of help to deal with those issues that may constrain or facilitate its development and growth. 
As an integrative approach (Carr 2006; Dallos and Urry 1999), IFAIM assumes that different theoretical models are different languages used to attribute meaning to the families' experiences. Professionals can incorporate, in practice, contributions from different approaches as long as: these languages are not dissonant with the family's preferred views of itself; the professional is guided by the family in the choice of those languages; the family's sense of authorship and autonomy is preserved and promoted; and the family is able to perceive itself as competent and to see its knowledge, competencies, preferences, and wishes respected and supported by the IFAIM team.

IFAIM is organized around a set of essential principals, assumptions and values, aimed at guaranteeing its coherence. The team's work is to be routinely evaluated in regard to these core fundamentals. Among these are: (a) a belief in the socially constructed nature of reality (Hoyt 1998); (b) a belief in the centrality of language and narrative in the organization of the human experience (Hoyt 1998; Strong 2002); (c) the privilege of a systemic and ecological framework (Vetere and Dallos 2003); (d) a strength and resilience-oriented perspective on family adaptation (Saleebey 2002; Walsh 2006a, b); (e) the primacy of children's and youth's safety and a commitment to respectful and violence-free relations; and (f) the need to maintain uncertainty and doubt, though in an organized and goalorientated fashion, when conducting risk assessment and elaborating case judgments and reports (Munro 2008). A basic collaborative orientation is also a central tenet in IFAIM (Madsen 2007; Strong 2002).

The adoption of a collaborative perspective during assessment does not mean that problems are negated or minimized nor even that the family's perspective is dominant in defining the change objectives. On the contrary, it signifies that different means and pathways to achieve clearly established goals may exist and can be constructed collaboratively with the family. The collaborative perspective adopted in IFAIM refers to exploration of the family's preferred views of itself and preferred directions in life (goals, dreams, purposes) (Madsen 2007; White 2007), and whenever these are compatible with the child's safety, recruits them along with the family's strengths to help it change. Collaboration in the context of child protection also means transparency and responsibility; transparency in the sense that the family is clearly and carefully and respectfully informed about the indicators of change that must be met and the conditions for the child's safety and well-being that must be guaranteed (monitored and proved with clear evidence).

The family has the possibility of and the responsibility for choosing to try to change and accept the help that is offered, after having the opportunity to experiment in the context of assessment, or not. But it also means that professionals are open to hear the family's visions and positions from a non-judgmental stance and that they are available to go beyond the strictly necessary (meeting child's safety and well-being indicators) to search for that which is desired (the family's goals and dreams and preferred visions of themselves). As some authors have proposed, many abusive parents would rather perceive themselves differently but need help to re-author their lives and realize their preferred visions (Madsen 2007).

As others have reported doing (Lee et al. 2009), we have subscribed to an integrative factor lens in attempting to incorporate the best of research evidence in regard to the core features of multi-systemic evidence-based programs and in-home strength-based approaches to build a program suited to providing community-based services to multi-challenged families in a child protection and welfare context while attending to the particular needs of the Portuguese context.

IFAIM offers a disciplined, coherent approach to help professionals achieve and manage a difficult balance between coercion and negotiation, control and support, evidence 
and multiple visions, demand and understanding (Brymer and Phillips 2006; Walsh 2006a, b). The efforts of developing manuals and the evaluation of its training program (Melo and Alarcão 2011a) and implementation in local communities (Melo and Alarcão 2011b) create conditions for future research to assess its efficacy.

While no single component of IFAIM is, at its core, substantially different from the theories from which it emerges or the models that inspire it, their combination composes a special system having features that transcend the sum of its parts. The blending of different types of thinking constitutes a new kind of integrative process aimed at meeting the needs of families and the child protection system and, above all, protecting children.

\section{Comprehensive Case Hypotheses}

Hypotheses in IFAIM are collaboratively co-constructed with the family (Vetere and Dallos 2003). While seeking to know the family's versions of its story, professionals attempt to build preliminary drafts of alternative narratives in a comprehensive, respectful, and strength-based way. These possible alternative stories and understandings are negotiated with the family through the elaboration of reflexive questions (Tomm 1987), comments, or remarks that are then further commented on, revised, or elaborated by the family. In this recursive and dialogical negotiation, new and more useful information may emerge to inform assessment and intervention and support the family's change.

Inspired by a family resilience perspective (Walsh 2006a, b; Melo and Alarcão (2010) have proposed an alternative theoretical framework organized around the metaphor of challenge that is incorporated in the formulation of integrative case hypotheses in IFAIM to assist professionals not only in understanding the risks associated with living in poverty and facing multiple challenges, but also the strengths that may be developed in the face of adversity. In this framework, assessment and intervention take into consideration both the complex relation between the more material and functional aspects of multi-challenged families' lives and the more relational and structural dimensions of their lives. Hypotheses incorporate a possible understanding of how the family has dealt with numerous challenges in its life and how these may have contributed to the development of vulnerabilities associated with the current problems (e.g., child maltreatment) or to the development of strengths and solutions. For example, child neglect may come as a result of a complex interplay of factors associated with prolonged exposure to stressful environments, a paucity of learning, lack of opportunities, and the working overload of a primary caregiver who has trouble supervising children. On the other hand, those adverse conditions might have contributed to the family's cohesion and a positive sense of purpose in life that may be mobilized to assist caregivers in uniting strengths, improving mutual support, and making a better use of professional help to overcome the limitations posed by their impoverished living conditions.

The way a family deals with such core challenges is to be considered in relation to what we call preferred outcomes in IFAIM. The formulation of comprehensive hypotheses considers three preferred outcomes: (a) the children's safety and well-being, (b) the family's preferred visions and directions in life, (c) and the exercise of its right to freedom. In regard to the first dimension, research results are combined with the dominant sociocultural standards and local, culturally-specific knowledge in order to consider how a child's safety and well-being are to be defined and assessed. This assessment is based upon a certain number of safety indicators that need to be fulfilled so the child can be considered safe or as having essential conditions for a healthy development. The second dimension is clearly inspired by the work of Michael White (2007) and other narrative authors (Madsen 
2007). IFAIM proposes that children's safety and well-being will be better and more easily achieved when compatible with the family's preferred visions and directions in life (goals, hopes purposes, values). These preferred directions and states of intention are thought to provide energy and purposeful movement to the process of change. Finally, family problems are thought to be heightened by conditions of inflexibility, lack of options or creativity, and by a certain number of external circumstances (e.g., poor learning opportunities) that limit the family's capacity to make informed decisions and deal responsibly with the consequences of its choices. IFAIM assumes, therefore, that professionals must help families exercise their right to freedom. It is understood that in order to do this, families must have not only legal information about their rights and duties in cases of child protection, information about their communities, and access to different sources of and means to improve their living conditions, but also, and above all, have information about themselves that makes a difference (Bateson 2000) in the activation and development of new skills, narratives, and solutions. IFAIM assumes a healthy family is able to create meaningful information about its life, to know its own learning mechanisms, to generate alternatives, and to make informed and conscious choices. IFAIM's focus on a family's exercise of its right to freedom calls the team to adopt a political stance in the sense that the family is invited to adopt critical and empowered positions in regard to the constraining factors of its reality.

Several dimensions of the family's development and of the family's ecology may constrain or potentiate the family's adaptation. Therefore, different levels of analysis (from the individual to the community and broad social factors) are considered in case conceptualization.

\section{Process of Change}

IFAIM's support for change work rests on the assumption that the family's change is sustained by the construction and validation of narratives which, when performed, guarantee the safety of children and youth and sustain the family's preferred visions and directions in life. IFAIM's success is, therefore, mainly evaluated by the attainment of these two goals, which are thought to be mutually reinforcing. This approach assumes that change happens through the expansion of novelty, understood as amplification of singularities (Elkaïm 1985) and moments of exception and successes in the realm of behaviors, emotions, and cognitions to which meanings are attributed. Family change is also thought to emerge out of the activation and amplification of the family's competencies, the repetition of small successful solutions (Berg and Kelly 2000), and the expansion of "news of a difference" (Andersen 1993, p. 342). These assumptions are shared by different theoretical approaches and offer, according to Rhodes (2008), a fertile ground for the integration of contributions from several models, as proposed in IFAIM.

IFAIM seeks not only to support families in identifying and amplifying changes but also to include them in the process of rewriting their stories. In this regard, White's (2007) narrative approach is particularly influential. IFAIM assumes that changes emerge from the dialectic interchange between the landscape of action and the landscape of meanings. Sluzki (1992) has proposed that family change occurs when there is flexibility and novelty in a number of organizing dimensions of family narratives such as time, space, causality, interactions, narrative mode, etc. IFAIM combines both Sluzki's and White's approaches in the conceptualization of narrative change. However, as Madsen (2007) states, a narrative orientation doesn't necessarily correspond to a work merely based on words. Often, multichallenged families, which have developed in disadvantaged social conditions, have a poor 
behavioral, emotional, and cognitive repertoire. They may present such crystallized narratives that a verbal and purely narrative work is not enough to help them perform effective changes. This concern is particularly relevant in situations where behavioral change is a requirement, as in child maltreatment and neglect cases. The process of change relies on the stimulation of the family's right to freedom, translated into a set of behavioral, emotional, and cognitive rehearsal and experimentation experiences that take place in the context of a secure and collaborative therapeutic relationship. Unique outcomes and singularities may emerge from these experiences that can be further elaborated in the realm of meanings and assist the family in re-authoring its life (White 2007).

Families are invited not only to different moments of collaborative and reflexive conversations but to more active experiential sessions prepared to facilitate the process of behavioral, cognitive, emotional, as well as discursive experimentation. The change rehearsal sessions tend to focus on the factors (or the family's positioning about them), which, according to the case conceptualization hypothesis, were thought to be constraining or potentiating the family's development and achievement of preferred outcomes. Results and exceptional outcomes in one area (e.g., domestic financial management) can be recruited to facilitate changes in other areas (e.g., parental decision making) through a focus on the family's strengths.

Support in IFAIM encompasses different types of intervention (therapeutic, social, community, educational) and targets different dimensions of the family's functioning and life (family internal organization, parental functions, professional inclusion, domestic management, community participation, etc.). The amplification and mobilization of internal and external strengths and resources is thought to be better achieved this way. IFAIM seeks, therefore, to improve the family's developmental conditions and facilitate change in order to achieve a better multi-systemic fit. Contributions from different models of parental, family, social, and community interventions can be integrated in the change rehearsal sessions as long as they are adapted in order to conform with IFAIM's collaborative stance and its core assumptions. For example, at a given moment the team may propose the parents' involvement in a moment of change rehearsal focused on discipline techniques and the quality of parent-child interactions. It may choose to organize those moments incorporating contributions from cognitive-behavioral to play therapy models. However, its purpose would not be to train the parents to act in a certain way. Instead, the intention may be to help the parents escape the domain of problems and experiment with alternative behaviors, cognitions, or emotions when interacting with their children that may fit their preferences and simultaneously guarantee the child's safety and well-being. In this example, the parents may be invited to identify and reinforce positive behaviors in their children during a situation of play. The professionals may, afterwards, invite the parents to reflect upon that moment with the purpose of finding useful meanings, strengths, competencies, and unique outcomes that may better serve those purposes. The team could explore with the parents alternative strategies for child rearing without imposing a unique expert-based solution. The exceptional events and singularities identified in that session could be elaborated in the landscape of meaning exploration (White 2007) and could contribute to strengthen a healthier and more viable narrative and corresponding performances.

\section{Stages of Implementation of IFAIM}

In practice, IFAIM is organized into 5 stages of implementation: (a) referral and request; (b) reception; (c) assessment; (d) support for change; and (e) follow-up and case closure. 
Each stage has specific objectives, guidelines, instruments, and strategies, which are described briefly in the following points.

\section{The Referral and Request Stage}

Families are usually referred to IFAIM by child protection services, courts, and other professionals or organizations from the community and the welfare system. The aim of the referral stage is to collect information about the family in order to outline the assessment stage, clarify roles and responsibilities, and articulate strategies between the IFAIM's team and other professionals since referred families are often multi-assisted. Another aim is to elaborate preliminary working hypotheses and to define the initial context as well as which elements of the IFAIM's team will be involved. A specific referral form is used to collect written information, but other contacts may be further established with the referring professional or organization in order to accomplish this stage's objectives. Two professionals (one of them being normally a psychologist and the other either a social worker or social educator) are assigned to the case. The family is invited to a reception meeting, which may occur in a traditional office setting or in the family's home. These two individuals work together throughout the case as co-therapists while a third individual and/or a supervisor helps them operate from multiple perspectives. The team usually asks the referring professional to assume social control functions explicitly in cases of child protection. The process and outcome of the family's collaboration with IFAIM's team will be reported to this individual, according to the terms to be agreed. This stage duration ranges from 1 day to 1 week.

\section{The Reception Stage}

The aim of the reception stage is to: (a) create a collaborative relationship with the family; (b) negotiate and define the outline of the request according to the referral and the family's wishes as well as to define the terms of the team's relationship with the family and with other professionals/organizations involved; and (c) define working strategies and negotiate objectives and procedures for the assessment stage. Specific competencies are expected from IFAIM's professionals in order to guarantee that this moment is future and solutionoriented as well as strength-based. The team is expected to show respect, concern, a nonjudgmental attitude, and a sincere desire to help. On the other hand, it must clearly state its commitment to the children's safety and well-being and to violence-free relationships. The reception stage is normally completed in one or two sessions.

\section{Assessment Stage}

The main objectives of the assessment stage are: (a) to assess the family's strengths and vulnerabilities in regard to the risk of (re)occurrence of future maltreatment and neglect; (b) to build hypotheses regarding the factors that may be constraining or potentiating the construction of safety and well-being conditions for children and youth as well as regarding the family's experience of its preferred views, directions in life, and states of intention; (c) to increase the family's willingness for change; (d) to assess the family's change potential, elaborate prognostics, and make recommendations in regard to the suitability of a support project aimed at the family's preservation or reunification; and (e) to define strategies for change and to elaborate an evaluation report. 
IFAIM integrates a risk assessment (an evaluation of the probability of re-occurrence of maltreatment and neglect and of conditions that may contribute to lower and manage the risk), a comprehensive assessment (an evaluation of parental capacity, child development, family functioning, and the family's environmental and social conditions that may contribute to problem maintenance or to solutions), and an assessment of the potential for change (the family's ability to change and benefit from professional support), all of which is done collaboratively, although integrating actuarial and clinical consensus-based methods (Munro 2008). This stage frequently incorporates some change rehearsal sessions focused on different dimensions of the family's and parental functioning in order to assess the family's change potential (Carr 2006; Fitzpatrick 1995).

An assessment protocol and a set of scales (concerning the areas of parental capacity, family dynamics, individual factors affecting parental capacity, social and environmental factors, and child adjustment) assist professionals in collecting and organizing information. Some instruments were specifically designed to meet IFAIM's purposes, and they guide the team to guarantee that no relevant information is neglected for assessment purposes, particularly in regard to children's safety and well-being. Guidelines also exist in regard to the organization of case information and file. The assessment reports have a standardized basic structure to report risk assessment, and comprehensive and potential for change assessment, always trying to describe the family's relationship with the problems and the solutions in a respectful, non-pathologizing way (Madsen 2007). Assessment is also based on some recommendations for evidence-based assessments in cases of child maltreatment and neglect (MacDonald 2001).

Although, standardized instruments may be incorporated in this stage they are mostly used as curious invitations to meet and know the family and their relation to problems (Anderson and Goolishian 1992). The reflexive, respectful and non-judgmental nature of the conversations helps the family explore, from unusual positions, narratives concerning itself, its environmental and social contexts, and its relationships with other systems. In this process, the family can explore new visions, dreams, hopes, aspirations and values. The assessment stage also focuses on solutions, objectives, purposes, and preferences and aims to help the family reclaim its sense of authorship and authority over its life. This stage's length may range from one to 6 months, with an average duration of 3 months.

\section{Stage of Support for Change}

The objectives of the support for change stage include: (a) to increase the security and well-being of family members, particularly of children; (b) to increase the family's perception of living according to its preferred visions and directions in life; (c) to increase the family's capacity to exercise the right to freedom; (d) to increase family resilience processes and the family's capacity to deal with multiple challenges; (e) to increase the quality of the family's social living conditions and/or its members' capacity to improve them; (f) to increase parental capacity regarding the satisfaction of children's needs for basic care, emotional security, guidance and limit setting, physical safety, and stimulation associated with positive development; and $(\mathrm{g})$ to decrease the problems and suffering as perceived by the family.

IFAIM's team and the family, as well as other significant people when appropriate, negotiate change objectives and elaborate a support project to be implemented in this stage, although changes also are often initiated during assessment. The support for change stage is focused on the negotiation and accomplishment of a certain number of clear objectives. 
For each objective there must be a definition of concrete indicators of changes, particularly in regard to children's safety and well-being. The support plans must take into consideration the processes and factors considered to be constraining or facilitating the preferred outcomes in IFAIM and the family's adaptation according to the case comprehensive hypotheses. These factors may include functional aspects of parenting and family functioning or more structural and organizational dimensions. Attention can be given to environmental and social dimensions that constrain or facilitate the family's adjustment, as well as to the family's relationship with other systems. Change projects, particularly the ones focused on functional dimensions, tend to be negotiated in detail and formalized in written change agreement contracts.

The support for change stage is organized to activate the family's exercise of the right to freedom. This stage combines characteristics of clinical, educational, social, and community work. Integrative family sessions are a common feature of all cases. In these sessions, the outcome and process of all change rehearsal sessions are discussed with the family with the objective of fostering the (re)construction of more flexible, satisfying, liberating, and caring family narratives. Integrative family sessions aim to increase the family's consciousness about the factors that influence its members' safety and well-being and increase a sense of authorship. This stage's length may extend for 1 year.

\section{Closure and Follow-Up}

The main objectives of the final stage are to promote the maintenance of changes and to evaluate their relevance and efficacy in reaching the desired goals. Networking interventions are particularly important and are incorporated in this stage along with narrative practices of acknowledgement and recognition of the family's accomplishments (White 2007). The IFAIM's team may propose (directly or through referral) family strengthening activities or community involvement programs, leisure activities, voluntary work, or projects focused on the development of skills that may help the family to better negotiate its social position, make use of available, resources or even contribute to community development (Rojano 2004). By this time sessions should be spaced farther apart than during the previous stage. The closure sessions should provide the family with opportunities to amplify, validate, and celebrate change (White 2007; White and Epston 1990). This stages' length ranges from 6-months to a year.

In this final stage, the IFAIM's team prepares a final report for the referral entity in which the work developed with the family and its outcomes, with particular emphasis on children's safety and well-being, are described. Recommendations are made in regard to the family preservation or reunification, when applicable, though this may happen sooner.

Case Example

\section{Referral}

The Silva family (information about the family has been disguised to protect the family's confidentiality, although it has consented to providing data for research and publication) was referred by the court through a multidisciplinary court support team. Four boys (between 2 and 10 years-old) had been removed from the home and placed in foster care 9 months prior to the referral, due mainly to physical (e.g., poor hygiene care and feeding 
habits), supervisory (e.g., children were left unsupervised outside the house), and environmental child neglect (e.g., the house presented many hazards, children played close to sharp farming equipment and all sorts of chemicals used in agriculture, house exterior and some rooms had spread household waste including knives or open cans; there was no bathroom). Some of the children had some marks of physical injuries (e.g., burn marks, animal bite marks). The children had lived with their mother and maternal grandparents in an interior and rural area of Portugal characterized by social and economic deprivation. The father of the children had abandoned the household some weeks prior to the referral and the IFAIM team never had contact with him. The family had been known by the local social services for 15 years and was considered to be "extremely resistant to change," and "unaware and unable to understand the dangers their children were exposed to." The grandparents wanted to assume legal custody of the children considering that their competence could more easily be recognized and that that should be enough for the children to be considered safe to return home. The family expressed a deep desire and willingness "to do whatever it takes to have the children back home."

IFAIM's assigned core team was composed of a psychologist (the first author) and a social educator. The team agreed to conduct a risk, comprehensive and potential for change assessment and inform the court accordingly. Based on the information provided during the referral, and given the family's socio-cultural context, a preliminary hypothesis was that the family's care giving style could be grounded in specific cultural roots. It was quite typical for families from the rural communities of Portugal to have their children raised with poor supervision, exposed to dangers but also learning to deal with them. Hygiene habits, for example, are still, in many families, the same as when the sanitary conditions and the knowledge about appropriate care were very limited in rural Portugal. Therefore, the team considered that the socio-cultural environment may have limited the family's right to freedom, restraining learning opportunities and, particularly, the development of some parenting abilities considered fundamental by the child protection system.

The strong attention given to the grandparents in the referral and the actions taken by them to assume responsibility for the children made the team advance with a complementary hypothesis. It could be that due to the demands of the family's harsh life and due to cultural factors (e.g., obedience to the elders in the family) the care giving roles were not clearly defined within the family. On the one hand, this could have contributed to some vulnerability in the supervision practices, which seemed to be established according to the grandparents' norms. On the other hand, neglectful behaviors could be somehow related to the mother feeling unrecognized in her care giving competence. That is, the mother was the only one in the family who could hardly read or write, which seemed to be highly valued in the family, since some of its members, including the grandfather, had had adult education classes; during conversations the grandparents frequently stated "she doesn't understand" or "doesn't know". These hypotheses were the first step in creating comprehensive and integrative case formulations, which would guide the professionals in their dialogues with the family and be revised and enriched by the assessment process and the family's responses. They offered a first alternative to the idea transmitted during referral that the family "didn't care," "was neglectful," and had "little potential to change." They were also enriched during assessment by an attempt to understand the family's experiences, its strengths, and the way it has dealt with multiple challenges and built strengths along the way. The hypotheses proved to be useful since the family not only validated them during assessment but also was able to use the information produced to create openings to change while maintaining a sense of family competence and authorship. 


\section{Reception}

In the initial interview, which took place in the family's home, it was evident that the family felt deeply unappreciated and stigmatized in previous contacts with the child protection and welfare system. The team explored their strong sense of commitment to each other, the values of cohesion and family preservation, and how the family felt deeply disturbed by the children's removal from the home.

The family showed a strong sense of pride in regard to their achievements in overcoming hardship and a strong affection for the children. The team was able to join the family, offering help so the family's strengths could be identified (mapping and seeking to amplify those evident during the sessions) and eventual vulnerabilities overcome. The family had made some improvements in the house (e.g., building a kitchen, a bathroom, and new rooms), which they proudly wanted to show to the IFAM's team.

\section{Assessment}

The team initiated with a concern to understand the family's history and how it dealt with multiple challenges throughout its life. Shortly after beginning the assessment, and guided by the hypothesis that the mother might need space to have her voice fully expressed, the team proposed to do some sessions only with the mother. In one session she disclosed being unsatisfied with her life and narrated a history of marital violence from which she wanted to depart and which seemed to have constrained her development and parenting capacity. The effects of violence in her life as well as socio-cultural constraints were mapped. Unique outcomes in regard to a sense of authorship and a preferred vision of herself were explored in the realm of both action and identity. She learned to rely on the support of the grandparents to educate her children, face her husband through divorce, and define her life project and identity. The grandparents' support was essential since the mother had neither financial capacity nor felt capable of raising four children by herself. Individual sessions provided support for the mother to review the narratives sustaining her identity in order to assume authorship and a preferred vision of herself, which included assuming a primary care giving role. Specific actions were jointly planned in regard to the mother's professional development (e.g., improving her qualifications), financial condition (e.g., looking for financial support and job opportunities), and the reorganization of her and her children's rooms in the house. The latter was done according to her preferences and after negotiation with the grandparents given that the children used to sleep in a bedroom near the grandparents since they insisted on taking direct and primary care of them. During assessment the mother proposed to bring them closer to her.

In the course of assessment the family spontaneously made improvements in the house (e.g., the mother decorated her and her children's rooms; bought personalized hygiene items for each child; the grandmother decided to redecorate the common living room and freshen it). The team privileged reflexive questioning even while using standardized instruments (e.g., "why do you think this question [included in a questionnaire assessing children's basic care] is included here?" "How can this help your children?" "What can happen in terms of their health?" "Does this question make sense to you?"). This was a concern that was maintained also during skill building and more educational sessions (e.g., focused on children's safety, health, hygiene).

During integrative family sessions the team invited the mother and the grandparents to explore how some cultural discourses might have influenced their family life and how they constrained their purposes. In those sessions, the family agreed that the mother should 
assume the primary care giving role. The grandparents recognized her competence to do so while the mother was able to openly express how their support was appreciated and valued, particularly since it would be very difficult for her to care for four children without support and with limited resources. A comprehension that the family's communication was not always effective was achieved. A strong sense of cohesion, positive affection, and mutual support were identified as some of the family's main strengths.

The team assisted the family members in preparing and managing meetings with other professionals (e.g., foster institutions, local social security) in order to define change objectives, seek local resources and appropriate support, and to address other dimensions of their lives (e.g., improving the mothers' financial autonomy) in an empowered and autonomous way.

At a given point, the team asked the court permission to take the children home once a week for 2 or $3 \mathrm{~h}$. During that time the family agreed to provide the children with a bath, prepare dinner, and have a meal with them. Some free play time was also possible. These meetings were prepared for with the family in order to create small change rehearsal opportunities that were an essential component of the assessment of the family's change potential. Family sessions were scheduled for the day after these home visits in order to evaluate them. The team invited the family to focus both on their strengths and positive achievements and on the vulnerabilities and aspects of the child rearing practices that could be improved. Small objectives and plans were negotiated for the next sessions. The core assessment ended in 3 months and the team elaborated a report that was sent to the court after being discussed with the family.

\section{Support-for-Change}

Compromises for change were negotiated and contracted to achieve the following objectives: (a) to improve the quality of the interaction with the children and increase emotional closeness and the quality of family involvement moments; (b) to increase maternal supervision capacity in order to prevent domestic injuries and to increase the capacity to organize domestic tasks and reconcile them with child care and attention; (c) to improve maternal skills in regard to child orientation, limit setting, ability to mediate conflict, and to use of praises and social reinforcements of the children's self-esteem; (d) to reinforce the mothers' authority as the primary caregiver and promote her autonomy; and (e) to improve family communication and the efficacy of the support provided by the grandparents. The team provided very close support, often scheduling 2 weekly sessions during the 5 months of the core support for change stage. About half of the sessions during this time included weekly home visits with the children. During the in-home sessions the team became an active witness of the process of change and could help the family identify and amplify moments of competence. Narrative intentions guided the professionals in offering support for the elaboration and expansion of unique and preferred outcomes as well as their meanings and implications. Some of the family sessions were dedicated to the rehearsal of alternative family communication, mutual help, and appreciation patterns and strategies.

Significant improvements were made in regard to all of the objectives contracted for with the family. The mother responded with special enthusiasm to the re-authoring invitations elaborated by the team. Both the progress and setbacks were objects of joint analysis. In certain moments, it was necessary to remind the family that some changes related to safety were fundamental to reunification. The children validated change while praising the mother and grandparents, saying things were "different" and "better" or making positive remarks about the new organization of the house, the routines and chores. 
At a given moment, and considering the importance of confirming the changes and validating them, the IFAIM's team suggested to the multidisciplinary team that assisted the court in case assessment and monitoring to perform monitoring visits to the family. The children returned home by court order 8 months after the first contact with IFAIM's team.

Follow-Up

During the follow-up period the IFAIM team tried to help the family create a support and monitoring network in the community, seeking to build collaborative relations between the family, the schools, the nursery, health services, and social security. It was expected that this network could become a validating audience. Other areas of collaboration were considered, such as children's leisure time, the support to the mother so she could develop skills for helping the children in school matters, and the elaboration and implementation of an individualized developmental stimulation program. The follow-up stage was still in course when the first author moved to a new job and had to be replaced. Therefore, information about the end of this stage and case closure is incomplete.

\section{Conclusion}

The IFAIM approach was designed to fill a gap in the Portuguese child protection and social services fields of action, and to optimize the resources available at the Centers for Family Support and Parental Counseling in order to meet the specific needs of multichallenged families with at psychosocial risk, maltreated, or neglected children and youth as well as the needs of the Portuguese child protection system. The model integrates contributions from several family therapy approaches and social interventions, addressing clinical, educational, social, community, and forensic concerns while maintaining a systemic, collaborative, narrative and strength-based orientation and trying to provide a tailormade and integrative support for families facing complex problems. An integrative model of this nature is something of a novelty in the Portuguese family-based services, particularly one that is being organized in order to be disseminated and evaluated. IFAIM is manualized and has a specific training program that is available and under evaluation. Evaluation of IFAIM's efficacy and effectiveness is warranted. A current research project is underway in Portugal. The goal is to conduct a preliminary evaluation of IFAIM's process and outcome and future research is welcomed to elucidate the mechanisms involved in the support provided and in the change processes. Comparison with other programs and intervention modalities as well as cross-cultural evaluations should be considered.

Acknowledgments The present work was supported by a doctoral scholarship (SFRH/BD/39912/2007) attributed to the first author by the Foundation for Science and Technology, Portugal.

\section{References}

Andersen, T. (1993). See and hear, and be seen and heard. In S. Friedman (Ed.), The new language of change. Constructive collaboration in psychotherapy (pp. 303-322). New York: The Guilford Press.

Anderson, H., \& Goolishian, H. (1992). The client is the expert: A not-knowing approach to therapy. In S. McNamee \& K. Gergen (Eds.), Social construction and the therapeutic process (pp. 25-39). Newbury Park, CA: Sage. 
Arditti, J., Burton, L., \& Neeves-Botelho, S. (2010). Maternal distress and parenting in the context of cumulative disadvantage. Family Process, 49(2), 142-164.

Baird, C., \& Wagner, D. (2000). The relative validity of actuarial and consensus-based risk assessment systems. Children and Youth Services Review, 22(11/12), 839-871.

Barth, R., Greeson, J. K. P., Guo, S., Green, R. L., Hurley, S., \& Sisson, J. (2007). Changes in family functioning and child behavior following intensive in-home therapy. Children and Youth Services Review, 29, 988-1009.

Bateson, G. (2000). Steps to an ecology of mind. Chicago: University of Chicago Press. (Originally published in 1972).

Benard, B. (2006). Using strengths-based practice to tap the resilience of families. In D. Saleebey (Ed.), Strengths perspective in social work practice (4th ed., pp. 197-220). Boston, MA: Allyn and Bacon.

Berg, I. K., \& Kelly, S. (2000). Building solutions in child protective services. New York: Norton and Company.

Brown, P., \& Dean, S. (2002). Assessment as an intervention in the child and family forensic setting. Professional Psychology: Research and Practice, 33(3), 289-293.

Brunk, M., Hengeller, S. W., \& Whelan, J. P. (1987). Comparison of multisystemic therapy and parent training in the brief treatment of child abuse and neglect. Journal of Consulting and Clinical Psychology, 55, 171-178.

Brymer, L. K., \& Phillips, J. M. (2006). Contextual meanings in action: Integration of social work and family therapy in child protective services. Journal of Systemic Therapies, 25(2), 12-23.

Budd, K. S., Poindexter, L. M., Felix, E. D., \& Naik-Polan, A. T. (2001). Clinical assessment of parents in child protection cases: An empirical analysis. Law and Human Behavior, 25(1), 93-108.

Cancrini, L., De Gregorio, F., \& Nocerino, S. (1997). Las famílias multiproblemáticas. In M. Coletti \& J. L. Linares (Eds.), Las famılias multiproblemáticas [The multiproblem families] (pp. 45-82). Barcelona: Paidós.

Carr, A. (2006). Family therapy. Concepts, process and practice (2nd ed.). Chichester: Wiley.

Cirillo, S., \& Di Blasio, P. (1992). Families that abuse. New York: W. W. Norton and Company.

Comissão Nacional de Proteç̧ão de Crianças e Jovens em Risco [CNPCJR, National Comission for the Protection of At-risk Children, Youth]. (2009). Relatório anual de avaliação das actividades das comissóes de proteç̧ão de crianças e jovens [Annual reporto of evaluation of the acticities of the comissions for protection of children and youth]. Lisboa: Comissão Nacional de Protecção de Crianças e Jovens em Risco.

Corcoran, J. (2000). Family treatment with child maltreatment using family preservation approaches. In J. Corcoran (Ed.), Evidence-based social work practice with families: A lifespan approach (pp. 76-123). New York: Springer.

Cunningham, P. B., \& Henggeler, S. W. (1999). Engaging multiproblem families in treatment: Lessons learned throughout the development of multisystemic therapy. Family Process, 38, 265-281.

Czyszczon, G., \& Lynch, M. (2010). Families in crisis: Resilience-based interventions and in-home family therapy. Retrieved from http://counselingoutfitters.com/vistas/vistas10/Article_17.pdf.

Dallos, R., \& Urry, A. (1999). Abandoning our parents and grandparents: Does social construction mean the end of systemic therapy? Journal of Family Therapy, 21(2), 161-186.

Department of Health. (2000). Framework for the assessment of children in need and their families. London: Stationery Office.

Doherty, W. J., \& Beaton, J. M. (2000). Family therapists, community, and civic renewal. Family Process, 39(2), 149-161.

Elkaïm, M. (1985). From general laws to singularities. Family Process, 24, 151-164.

Fitzpatrick, G. (1995). Assessing treatability. In P. Reder \& C. Lucey (Eds.), Assessment of parenting. Psychiatric and psychological contributions (pp. 102-117). Hove: Brunner-Routledge.

Frankel, H., \& Frankel, S. (2007). Family therapy, family practice, and child and family poverty: Historical perspectives and recent developments. Journal of Family Social Work, 10(4), 43-80.

Grimes, M. E., \& McElwain, A. D. (2008). Marriage and family therapy with low-income clients: Professional, ethical and clinical issues. Contemporary Family Therapy, 30, 220-232.

Henggeler, S. W., Melton, G. B., \& Smith, L. A. (1992). Family preservation using multisystemic therapy: An effective alternative to incarcerating serious juvenile offenders. Journal of Consulting and Clinical Psychology, 60, 953-961.

Hogue, A., Liddle, H. A., Becker, D., \& Johnson-Leckrone, J. (2002). Family-based prevention counseling for high-risk young adolescents: Immediate outcomes. Journal of Community Psychology, 30(1), 1-22.

Hoyt, M. F. (1998). Introduction. In M. F. Hoyt (Ed.), The handbook of constructive therapies: Innovative approaches from leading practitioners (pp. 1-26). San Francisco: Jossey-Bass. 
Lee, M. Y., Greene, G. J., Hsu, K., Solovey, A., Grove, D., Fraser, J. S., et al. (2009). Utilizing family strengths and resilience: Integrative family and systems treatment with children and adolescents with severe emotional and behavioral problems. Family Process, 48(3), 395-416.

Liddle, H. (2004). Family-based therapies for adolescent alcohol and drug use: Research contributions and future research needs. Addiction, 99(2), 76-92.

MacDonald, G. (2001). Effective interventions for child abuse and neglect. An evidence-based approach to planning and evaluating interventions. West Sussex: Wiley.

Madsen, W. C. (2007). Collaborative therapy with multi-stressed families (2nd ed.). New York: The Guilford Press.

Melo, A. T., \& Alarcão, M. (2010). From multi-problem to multi-challenged families: A Multiple Challenges Integrative Model. Manuscript in preparation.

Melo, A. T., \& Alarcão, M. (2011a). Training professionals in community settings: Change processes and outcomes in a child protection context. Manuscript submitted to publication.

Melo, A. T., \& Alarcão, M. (2011b). Implementation of a community-based family-centered program in Portugal: A multiple case study evaluation. Manuscript submitted to publication.

Munro, E. (2008). Effective child protection (2nd ed.). London: Sage.

Palazzoli, M. S., Boscolo, L., Cecchin, G., \& Prata, G. (1980). Hypothesizing, circularity, neutrality: Three guidelines for the conductor of the session. Family Process, 19(1), 3-12.

Reder, P., \& Lucey, C. (Eds.). (1995). Assessment of parenting. Psychiatric and psychological contributions. Hove: Brunner-Routledge.

Relvas, A. P. (1996). A co-construção da hipótese sistémica em terapia familiar [The co-construction of systemic hypothesis in family therapy]. Análise Psicológica, 4(XIV), 563-579.

Rhodes, P. (2008). Amplifying deviations in family interactions: Guidelines for trainees in post-milan family therapy. Australian and New Zealand Journal of Family Therapy, 29(1), 34-39.

Rojano, R. (2004). The practice of community family therapy. Family Process, 43(1), 59-77.

Saleebey, D. (2002). The strengths perspective in social work practice (3rd ed.). Boston: Allyn and Bacon.

Sessions, P., \& Lightburn, A. (2006). What is community-based clinical practice? Traditions and transformations. In A. Lightburn \& P. Sessions (Eds.), Handbook of community-based clinical practice (pp. 3-18). New York: Oxford University Press.

Sharlin, S. A., \& Shamai, M. (2000). Therapeutic intervention with poor, unorganized families. From distress to hope. New York: The Haworth Press.

Sluzki, C. E. (1992). Transformations: A blueprint for narrative changes in therapy. Family Process, 31(3), 217-230.

Sousa, L., \& Eusébio, C. (2005). When multi-problem poor individual's values meet practitioners' values. Journal of Community and Applied Social Psychology, 15(5), 353-367.

Sousa, L., Ribeiro, C., \& Rodrigues, S. (2007). Are practitioners incorporating a strengths-focused approach when working with multi-problem poor families? Journal of Community Applied Social Psychology, 17, 53-66.

Sprenkle, D. H., Davis, S. D., \& Lebow, J. L. (2009). Common factors in couple and family therapy. The overlooked foundation for effective practice. New York: The Guilford Press.

Strong, T. (2002). Collaborative "expertise": After the discursive turn. Journal of Psychotherapy Integration, 12(2), 218-232.

Tomm, K. (1987). Interventive interviewing: Part II. Reflexive questioning as a means to enable selfhealing. Family Process, 26(2), 167-183.

Torres, A. (Coord.) (2008). Estudo de diagnóstico e de avaliação das comissões de protecção de crianças e jovens [Diagnostic and evaluation study of the comissions of protection of children and youth]. Lisboa: Centro de Investigação e Estudos de Sociologia, Instituto Superior de Ciências do Trabalho e da Empresa.

Turnell, A., \& Edwards, S. (1999). Signs of safety. A solution and safety oriented approach to child protection casework. New York: W. W. Norton and Company.

Vetere, A., \& Dallos, R. (2003). Working systemically with families. Formulation, intervention and evaluation. London: Karnac Books.

Walsh, F. (2006a). Strengthening family resilience (2nd ed.). New York: The Guilford Press.

Walsh, T. (2006b). Two sides of the same coin: Ambiguity and complexity in child protection work. Journal of Systemic Therapies, 25(2), 38-49.

White, M. (2007). Maps of narrative practice. New York: W. W. Norton and Company.

White, M., \& Epston, D. (1990). Narrative means to therapeutic ends. New York: Norton. 